\title{
Strategic Scenario Construction Made Easy
}

\author{
Duus, Henrik Johannsen
}

Document Version

Accepted author manuscript

Published in:

International Journal of Foresight and Innovation Policy

DOI:

10.1504/IJFIP.2016.078349

Publication date:

2016

License

Unspecified

Citation for published version (APA):

Duus, H. J. (2016). Strategic Scenario Construction Made Easy. International Journal of Foresight and Innovation Policy, 11(1/2/3), 167-183. https://doi.org/10.1504/IJFIP.2016.078349

Link to publication in CBS Research Portal

\section{General rights}

Copyright and moral rights for the publications made accessible in the public portal are retained by the authors and/or other copyright owners and it is a condition of accessing publications that users recognise and abide by the legal requirements associated with these rights.

Take down policy

If you believe that this document breaches copyright please contact us (research.lib@cbs.dk) providing details, and we will remove access to the work immediately and investigate your claim. 


\section{Strategic Scenario Construction Made Easy Henrik Johannsen Duus}

Journal article (Post print version)

Cite: Strategic Scenario Construction Made Easy. / Duus, Henrik Johannsen. In: International Journal of Foresight and Innovation Policy, Vol. 11, No. 1/2/3, २016, p. 167-183.

DOI: http://dx.doi.org/10.1504//JFIP.2016.078349

Uploaded to Research@CBS: September २०16 
Article for

International Journal of Foresight and Innovation Policy

\title{
STRATEGIC SCENARIO CONSTRUCTION MADE EASY
}

by

\author{
Henrik Johannsen Duus, PhD \\ Associate Professor \\ Department of Marketing \\ Copenhagen Business School \\ Solbjerg Plads 3 C 3.24. \\ DK- 2000 Frederiksberg \\ Denmark \\ Ph.: +4538152124 \\ Fax: +4538152102 \\ Email: hjd.markto@cbs.dk
}

\begin{abstract}
Scenario planning is a well-known way to develop corporate strategy by creating multiple images of alternative futures. Yet although scenario planning grew from very hands-on strategy development efforts in the military and from operations research dedicated to solving practical problems, the use of scenarios in business has in many cases remained a cumbersome affair. Very often a large group of consultants, employees and staff is involved in the development of scenarios and strategies, thus making the whole process expensive in terms of time, money and human resources. In response, this article uses insights from the area of strategic forecasting (of which scenario planning is a proper subset) and experiences gained from a recent course in that area to develop a simpler, more direct, hands-on method for scenario construction and to provide several ideas for scenario construction that can be used by a broader circle of firms.
\end{abstract}

Key words: futures research, corporate strategy, organisational development, scenario planning, external analysis, strategic forecasting, multiple scenario methodology, innovation.

\section{Autobiographical note:}

Dr. Henrik Johannsen Duus is an associate professor at the Department of Marketing at Copenhagen Business School. His current research interests are strategic forecasting and innovation/entrepreneurship. He has previously conducted research in market orientation, supply-side marketing, innovation management, online learning, international business-to-business marketing and the history and philosophy of economic theory. He has taught extensively in marketing and international business and has a practical background in financial analysis.

\section{Acknowledgements:}

The author would like to thank the two anonymous reviewers and the editor for their helpful comments in preparing this article.

In addition, this article has benefited from discussions and comments from a number of researchers, among whom Claus G.

Jacobsen and Henrik A. Sørensen (both Copenhagen Business School) have been the most important. Any oversimplification or outright errors that remain are entirely my own responsibility. 


\section{STRATEGIC SCENARIO CONSTRUCTION MADE EASY}

Abstract: Scenario planning is a well-known way to develop corporate strategy by creating multiple images of alternative futures. Yet although scenario planning grew from very handson strategy development efforts in the military and from operations research dedicated to solving practical problems, the use of scenarios in business has in many cases remained a cumbersome affair. Very often a large group of consultants, employees and staff is involved in the development of scenarios and strategies, thus making the whole process expensive in terms of time, money and human resources. In response, this article uses insights from the area of strategic forecasting (of which scenario planning is a proper subset) and experiences gained from a recent course in that area to develop a simpler, more direct, hands-on method for scenario construction and to provide several ideas for scenario construction that can be used by a broader circle of firms.

Key words: futures research, corporate strategy, organisational development, scenario planning, external analysis, strategic forecasting, multiple scenario methodology, innovation.

\section{INTRODUCTION}

Increasing turbulence and complexity in the environment necessitate that firms spend more time thinking strategically about the future (Duus, 2013). Scenario based planning - which attempts to create multiple alternative images of possible futures to consider in corporate strategy making - is one way of doing exactly this (Heijden, 2005).

However, scenario construction is not always easy and straightforward. We may distinguish between two cases: one in which a department of the firm responsible for strategic planning formulates scenarios that are to be accepted by the management and another, in which outside consultants are brought in.

Especially in the latter case the process may tend to involve increasingly larger numbers of staff, each of whom may spend up to hundreds of working hours on scenario workshops and strategy seminars on constructing scenarios. The use of expensive consultants and analysts to 
support this process may add further to the cost burden. And demands for such consultants have been growing rapidly, especially with the spread of scenario-based planning to hitherto inexperienced organisations such as public sector organisations.

But even in the first case, scenario construction may become very complicated and take up substantial amounts of time. This is very much the case when scenario construction efforts involve developments in the macro-environment. Moreover, not all firms are sufficiently large to support their own departments dedicated to strategic planning. Needless to say, scenarios are often used in larger firms that are able to shoulder the costs in terms of time, personnel resources and money.

To alleviate the problems that may arise in both cases, the present article develops and describes a method that can enable a smaller circle of persons to create scenarios faster than the usual method. The method is especially well suited for dealing with trends and factors in the macro-environment. This method enables firms to cut down on the time, money and personnel resources spent. In addition, the saved costs open up for the possibility that small and medium-sized enterprises may make greater use of scenario planning.

This article proceeds in three steps. First, a brisk overview of the historical, theoretical and methodological context of scenario construction is presented. This overview does not attempt to chronicle all the intricacies of scenario construction and scenario planning. It limits itself to an exposition necessary for setting the stage for a new method of scenario construction. Second, an alternative scenario construction method is presented. The method was initially developed as a high-speed, straightforward way to enable small teams of young executives taking a short business course in "strategic forecasting" to create multiple scenarios for a 
practical assignment. Third, the experiences gained are discussed and conclusions are drawn on how to utilise the method in business and research.

For its methodology, this article employs a combination of theory and empirical work. It utilises the theory and history of scenario construction and scenario planning in order to create an overview. It then uses the method of auto-ethnography to chronicle this author's work in planning and teaching a strategic forecasting course (Chang, 2008). In this method, theory and history are intertwined with an explorative quest, where this author's personal experiences constitute the empirical data (much like the diaries of early explorers of distant parts of the world). Embedded in this, the new scenario construction method is tried out on five student groups; these tests may be seen as experiments or mini-cases (Yin, 2009). Abductive reasoning, which employs logical inferences and creativity, is used to go from theory and experiential observations to the development of ideas, methods, implications and conclusions (Itoh, 1996; Yu, 1994).

There are of course limitations to this study. First, the use of qualitative methodology in the design and testing of the scenario construction method does impose limits on the generalisability. But the use of qualitative methodology is hardly uncommon in scenario construction efforts and may even be seen as a necessity in the case of a creative design of a new method (Itoh, 1996; Heijden, 2005). More limits are imposed by this method being embedded within an explicit strategic forecasting framework. This implies that attention is concentrated on the long-run macro issues and much less on issues in the immediate vicinity of the firm such as competitors and customers (Capon \& Hulbert, 1985; Capon \& Palij, 1994; Duus, 2013). However, this may also be seen as a strength, as it allows users of this method to concentrate on issues that are often given too little attention in strategic planning efforts. 
The heart of the matter is to chart long-run macro and meso events and use this knowledge to find strategic implications and assist in strategic change on lower levels of analysis, such as those of the firm and its markets (Duus, 2013).

\section{SCENARIO CONSTRUCTION IN THEORY AND PRACTICE}

The values of scenario construction in strategic planning in firms have long been recognised in broad circles. Long-run strategic decision making for a firm is essentially a question of going through seven different steps (Aaker, 2006; Ansoff and McDonell, 1990):
a) Creating a mission and vision for the firm
b) Analysing the present and future environment of the firm
c) Analysing the internal resources and characteristics of the firm
d) Assessing the connection (or lack of same) between $\mathrm{b}$ and $\mathrm{c}$
e) Developing strategies to increase the connection between $\mathrm{b}$ and $\mathrm{c}$
f) Choosing between the strategies
g) Implementing the selected strategies and evaluating results.

The use of scenarios may contribute to handling all seven steps, but more often than not, focus is on the first two steps in this sequence. Thus, the main difference between scenario planning and traditional corporate strategic planning may be that scenario planning explicitly seeks to handle indeterminateness and ambiguity in analysing the present and future. Whereas traditional corporate strategic planning searches for definitive answers to problems defined in the course of the strategy making process, scenario planning, by contrast (and in parallel to quantum physics and science fiction), envisions the future as a plurality 
(Georgantzas and Acar, 1995). Multiple alternative futures, which can form the basis for building options and action alternatives and hence, for strategy making and planning, are explicitly sought after (Aligica, 2007; Duus, 2013; Schoemaker, 1993). One aspect of introducing indeterminateness and ambiguity is that planning becomes a continuous learning exercise in the organisation and not the on-off activity to which the planning process often degenerates in organisations. This aspect of continuous learning also implies that the work of scenario construction almost becomes a kind of organisational development, involving large numbers of people in and outside the organisation (Bootz, 2010; Duijn \& Hartigh, 2009).

Viewed as a purely analytical undertaking seeking to increase options and action alternatives, scenario construction in business and the theory and methodology associated with it can be seen as a subset of a wider area called "strategic forecasting" (Capon \& Hulbert, 1985; Capon \& Palij, 1994; Duus, 1997, 1999, 2013). Strategic forecasting can be defined as "the area of business economics that deals with the study and the practical application of methods, theories, models and techniques for long-term analysis of the non-proximate environment of the firm with the purpose of conducting strategic change" (Duus, (2013), pp. 364-365). Accordingly, it may be seen as a way of embracing "those types of long-term forecasts that are strategic for the firm" (Capon \& Palij, (1994), p. 340) or in a complimentary manner, a way to introduce "areas of analysis that are macroscopic, long-run and strategic in order to create innovation and change" (Duus, (2013), p. 372). The difference between strategic forecasting and other forms of analysis is illustrated in figure 1. 
XXXXXXXXXXXXXXXXXXXXXXXXXXXXXXXXXXXXXXXXXXXXXXXXX

INSERT FIGURE 1 HERE

FIGURE 1: STRATEGIC FORECASTING COMPARED TO

OTHER FORMS OF ANALYSIS

XXXXXXXXXXXXXXXXXXXXXXXXXXXXXXXXXXXXXXXXXXXXXXXXX

As mentioned, scenario construction may be seen as a subset of strategic forecasting that can be defined as the creation of multiple possible futures in order to support strategy making in business and (sometimes) politics (Godet and Roubelat, 1996; Lindgren and Bandhold, 2009; Ringland, 2002; Sharpe and Heijden, 2007). Such a creation may utilise methods that are already known and accessible to many students and practitioners of business and politics. For example, Bunn and Salo (1993) suggest that the difference between a forecast and a scenario may be more one of practical connotation than distinct methodology as data inputs to scenarios often depend on methodologies that are indistinguishable from those that would be present in a forecast (see, for example, Armstrong, 2001; Shim, 2000).

However, looking beyond the gathering and processing of data, extreme confusion exists as to what actually constitutes a viable method of scenario construction. In the words of Bradfield et al., "...there appears to be virtually no area in scenarios on which there is widespread consensus, the literature reveals a large number of different and at times conflicting definitions, characteristics, principles and methodological ideas about scenarios" (Bradfield et al., (2005), p. 796).

In point of fact, reviews of the scenario literature reveal that the area is characterised by a multitude of various approaches to scenario creation (Bradfield et al., 2005; Chermack, 
Lynham and Rouona, 2001; Heijden, 2005; Schnaars, 1987; Varum and Melo, 2010). This need not be a critical problem as there certainly may be more than one way of constructing scenarios.

Reviewing the literature, it is also obvious that one should make a distinction between publications that attempt to present a theoretical overview of the area and publications of a more pragmatic nature that attempt to provide users with step-by-step instructions and dos and don'ts.

But as many newcomers to the area of scenario construction have found out the hard way, the pragmatic literature seldom provides an adequate step-by-step description of how to go about constructing a scenario. A common problem is that the level of detail is limited to five or six fluffy points encouraging practitioners to, for example, decide on assumptions/drivers for change, bring drivers together, produce initial mini-scenarios, reduce to two or three scenarios, write the scenarios and identify issues arising. In this manner, too much is left to chance and scenarios may end up being constructed rather haphazardly, especially when scenario construction is attempted by novice users with a limited to average knowledge of economics and sociology. While such publications definitely have their merits in popularising the area and accustoming readers to thinking about scenarios as a possible and useful tool in strategy making, many fail to provide readers with a clear-cut modus operandi for constructing scenarios. It is in fact symptomatic of the state of practical scenario construction that one of the better methods for scenario construction is found in Porter (1985), a book whose main theme is not really scenario construction but rather competitive advantage. 
Furthermore, scenarios have long been associated with big government and big business. The development of a scenario methodology by Kahn (1965) for use in government and military planning in the sixties and seventies as well as the notable use of scenarios in big companies like Shell are cases in point (Bradfield et al., 2005; Heijden, 2005; Schoemaker and Heijden, 1992; Wack, 1985a, 1985b). Today, scenarios seem to be a well-established tool in medium to large-sized companies and government institutions (Cummings and Daellenbach, 2009; Rohrbeck and Gemünden, 2011; Rohrbeck, 2012; Schoemaker, 1995; Schwartz, 2007; Vecchiato and Roveda, 2010). This is actually the case to such an extent that going against the grain by attempting to use them in small businesses is seen as an extreme exception to the rule (see, for example, Foster, 1993).

One consequence of the simultaneous lack of a clear-cut methodology and the predominant use in big organisations is that scenario construction all too often develops into an expensive and esoteric exercise involving outside experts. An organisation may express a desire to attempt to use scenarios in planning and expensive management consultants may be hired to guide the scenario construction process. Due to an often expressed need for an open-ended "democratic" scenario construction process, a large number of people (often staff members) are invited to workshops and seminars in order to contribute with input and to engage in the writing process. This will naturally mean that costs may soar and personnel resources may end up being tied up over long stretches of time. All in all, the total number of working hours spent may easily climb into the thousands.

All this is somewhat paradoxical as the scenario methodology was initially used as a straightforward tool by a rather small number of strategists. This is readily seen from a quick glance at the historical development of scenario construction methodology. It was initially 
developed from military strategising and operations research after WWII (Ansoff and McDonell, 1990; Bradfield et al., 2005; Martinet, 2010). The earliest beginnings of scenario construction are found in the writings of officers like von Clausewitz and von Moltke (Bradfield et al., 2005; Heijden, 2005). In these settings scenarios were created by a limited number of top officers and specialists. The methodology was then gradually introduced into politics and business in the sixties and seventies, as noted earlier, most prominently by Kahn (1965) and later by Wack (1985a, 1985b) and Godet (Chermack, Lynham and Ruona, 2001; Godet and Roubelat, 1996). At this time it had not yet developed into the multi-person endeavour it is today. On the contrary, early scenario developers like Herman Kahn and later Pierre Wack could in many ways be seen as so unique that they single handedly may have been responsible for many scenarios.

The present problem that scenario construction may end up being a costly affair measured in time, money and personnel resources is nothing new (Heijden, 2005). It was inter alia pointed out by Mercer (1995a, 1995b), who successfully attempted to construct a simpler method for mass producing scenarios. This method, however, has ended up being so simple that too much is left to chance. In response, what is needed should analogously be a new scenario construction method aimed at gaining a higher level of detail, quality and applicability in business for both method and actual scenarios.

3. TOWARDS A HANDS-ON, STEP-BY-STEP METHOD FOR CONSTRUCTING SCENARIOS

Such a method emerged in the autumn of 2011, when I was responsible for teaching a (bachelor level) course in strategic forecasting at Copenhagen Business School (Denmark) to 
young executives (studying business on a part-time basis) employed in a wide range of companies. Most of the participants had another academic background from prior education. Lecturing was conducted by me and several experts from business and academia. The details are visible in figure 2.

\section{XXXXXXXXXXXXXXXXXXXXXXXXXXXXXXXXXXXXXXXXXXXXXXXXX}

INSERT FIGURE 2 HERE

FIGURE 2: THE COURSE IN STRATEGIC FORECASTING XXXXXXXXXXXXXXXXXXXXXXXXXXXXXXXXXXXXXXXXXXXXXXXXX

The planning of the course involved finding solutions to several problems. First and foremost, to be useful and understood, theory should be applied and not just taught by lecturing. Thus, the course should involve participants getting their hands dirty with practical assignments involving the collection and processing of data and the transformation of data into information and knowledge the participants would see as practical and useful. To this end, an exercise in scenario construction was chosen, as the gathering and processing of data input to scenarios by necessity involves a wide variety of theories, methodologies and approaches, all of which were taught in the lectures. This exercise was planned to run through the whole course as the single practical assignment that would keep the participants busy.

Straight from the beginning of the course, groups of an intended size of five were formed, each of which was given the assignment of writing a number of scenarios within an area freely chosen by the group. The scenarios were to be finished at the end of the course and presented in a written group report. 
In accordance with the course area of strategic forecasting, scenarios were to be thought of exclusively as macro-scenarios, each playing itself out on a high aggregation level. The participants were told that this was completely in keeping with the essence of strategic forecasting, which is precisely directing attention to the macroscopic long range issues and using that information to create strategic change and innovation in the individual firm (Duus, 2013). The curriculum of the course supported this completely. To illustrate the approach, one can point to China being widely considered a new frontier for Danish companies for export, investment and the establishment of subsidiaries. Hence, macro developments in Chinese society and the Chinese economy are of strategic importance for many firms in Denmark. It was thus no surprise that one group chose to construct scenarios about developments in China.

Individual oral exams, involving a discussion of the scenarios, theories and methodologies chosen as well as the applicability of the scenarios to the participants' own firms, completed the course.

The group work was seen as an integral part of the course and took place in rooms adjacent to the lecture hall. The last two sessions were reserved entirely for group work with coaching (see again figure 2). However, it was made clear that some private supplementary group discussions off campus were expected in order to complete the scenarios. These were seen as home assignments and part of the course and the hourly calculations for the course.

The group discussions was essentially self-organised by the groups and took in all cases the form of a free round table discussion that was to be coached by the two faculty members when participants asked for advice (see again figure 2). Both faculty members had many 
years of coaching experience and used a coaching strategy involving directing the participants' attention to gleaning information from secondary data and using creativity and logic to find patterns and most likely interpretations (Itoh, 1996; Yu, 1994). Apart from this, no special technique was used in the coaching.

The content of the lectures involved strategic forecasting theory, practical statistics, ethnography, strategic business cycle forecasting (using economic indicators) and financial forecasting (using financial technical analysis), futures studies and trend research, strategic management as well as some forms of technological forecasting (Duus, 2013; Martino, 1992; Pring, 2002). Thus the use and construction of the scenarios could be seen as a way of utilising most of the different tools commonly used to say something meaningful about the future (see figure 3). The main problem, however, was, as mentioned above, that the literature on scenario construction shows an uncanny lack of consensus, precision and practical straightforwardness. Hence, we could run the risk of confusing participants and wasting time in the process.

\section{XXXXXXXXXXXXXXXXXXXXXXXXXXXXXXXXXXXXXXXXXXXXXXXX \\ INSERT FIGURE 3 HERE \\ FIGURE 3: \\ INPUT AREAS TO THE SCENARIO CONSTRUCTION PROCESS XXXXXXXXXXXXXXXXXXXXXXXXXXXXXXXXXXXXXXXXXXXXXXXX}

To deal with this problem, I designed a 7-point scenario consistency test and a 14-point methodology for fast-tracked mass production of scenarios in the groups. A rigid step-by-step 
approach was intended to alleviate the participants' burden of finding their way through the literature and to allow them to focus on the actual construction of scenarios.

According to this approach, scenarios must be able to pass a 7-point test of consistency. In general, scenarios should:

1) Deviate from the present, i.e. they should show a future reality that differs from the present.

2) Be consistent with present day reality, i.e. they should present a narrative that could be argued to follow from the world of today.

3) Be probable, i.e. they should not be unrealistic.

4) Be of somewhat equal probability, i.e. all scenarios should be equally realistic.

5) Be internally consistent, i.e. the elements describing the scenarios should have a logical relation to each other.

6) Be distinct from each other.

7) Take all influential trends/drivers into account.

With the 7-point consistency test in mind, it would then be possible to apply the 14-point scenario construction method that - as the name implies - consists of the following 14 steps:

a) Identify and formulate the central problem (for example, 'Should we invest in the energy sector and in what part?'. 'What will be "the next big thing" in the IT/computer/electronics sector?'). 
b) Determine the time horizon (length in years) and level of analysis (macro, meso, micro) on the basis of (a). (Here a macro- or mesoscopic long-run perspective is usually chosen, thus enabling the full use of the strategic forecasting toolbox.)

c) Determine basic trends and/or drivers for developing the defined problem area (in casu the chosen sector). A trend is seen as a development over time and a driver is a factor contributing to one or more trend developments. Combine quantitative and qualitative methods.

d) Rank trends/drivers by predictability (i.e. likelihood to continue) and importance.

e) Eliminate unimportant trends/drivers from the analysis.

f) Choose (and thereby eliminate from the list) predictable trends/drivers (for example, demographic trends) to appear in every scenario constructed.

g) Identify co-variations of trends/drivers and combine trends/drivers, i.e. ask which trends/drivers are connected?

h) Eliminate impossible co-variations (for example, zero growth and full employment) from the analysis.

i) Continue with points (e), (f), (g) and (h) until only two trends/drivers remain.

j) Identify the extreme points for the two remaining trends/drivers so that they can be plotted in a coordinate system or (even better) in a four quadrant model.

k) Define, plot and name four scenarios in the coordinate system/the quadrant model.

1) Write out each scenario in a coherent narrative - so that they will fulfil the above seven steps in the consistency test.

m) Identify the need for additional information and data. Collect this information and these data and use them to make the scenarios more complete.

n) Find and describe the consequences for different relevant agents (countries, industries, organisations and firms) so that useful decisions may be facilitated. 
As mentioned, the discussions were organised in a free form with some coaching. This also implied that no formal discussion techniques were introduced. Groups were thus mostly selfmanaged and the ranking of trends and drivers by predictability and importance was supposed to be done spontaneously by the participants in accordance with the above step procedure.

\section{RESULTS}

The above 14-point method was, as mentioned, tried out and was found to enable the rapid generation of multiple scenarios by smaller groups, each consisting of an intended number of five persons (see figure 4).

XXXXXXXXXXXXXXXXXXXXXXXXXXXXXXXXXXXXXXXXXXXXXXXXXXX

INSERT FIGURE 4 HERE

FIGURE 4

SCENARIO GROUP ACTIVITY XXXXXXXXXXXXXXXXXXXXXXXXXXXXXXXXXXXXXXXXXXXXXXXXXXXX

All groups produced detailed written scenario reports of 7-11 pages per person (close to 10 pages was actually demanded by the coaches). These scenario reports included accounts of the whole step-by-step process and data collection. From the time budget in the course, it can be calculated that the participants spent around 30 hours per person on creating the scenarios and the reports. A very condensed example of the output from one of the groups is found in figure 5 . 
XXXXXXXXXXXXXXXXXXXXXXXXXXXXXXXXXXXXXXXXXXXXXXXXXXX

INSERT FIGURE 5 HERE

FIGURE 5

\section{SHORT EXAMPLE OF SCENARIOS FROM GROUP 3} XXXXXXXXXXXXXXXXXXXXXXXXXXXXXXXXXXXXXXXXXXXXXXXXXXXX

Data inputs were provided by scanning articles, books, the media as well as the internet. Model building and own calculations were done to some extent but mostly data, information and knowledge from sources that were deemed reliable were accepted and incorporated. However, experience suggests that participants benefited greatly from the lectures, the group manifestation of knowledge already held by the individuals and the allotted few hours of group coaching. Especially the fact that group members came from diverse backgrounds and thus were able to bring in cross-disciplinary knowledge may have contributed immensely to the process and enabled transdisciplinarity to arise (Rasmussen, Andersen and Borch, 2010).

This indicates that the 7-point consistency test and the 14-point method cannot stand alone. Still, it must be remembered that the participants were complete beginners at this game and that groups of around five people with diverse backgrounds, who have tried this a few times, may be able to generate scenarios very quickly. Thus, the theoretical input from the lectures may only be necessary for participants with no previous knowledge of the area. On the other hand, it may be beneficial to improve group discussions with more formal techniques (Brauers, 2004). 
The course evaluations showed an average satisfaction rating of 4.5 on a Likert 5-point scale (with 5 being the highest). But despite the apparent success of the course, a few participants expressed a certain amount of psychological uneasiness in dealing with several possible futures. This may speak in favour of the rare instances in which a select group attempts to create what can be called a baseline scenario methodology, where only one scenario is generated (Graf, 2002a; 2002b). Such a baseline scenario may of course be no more certain than most other scenarios; however, it may provide some participants with the feeling that a degree of certainty has been reached. Since it can be expected to contain different trends with a very diverse desirability, the amount of bias in a baseline scenario may be held on a marginal level. A practical illustration of how the focus on just one scenario - or rather, just one possible future - can lead to substantial insights is found in Tvede (2010). However, the creation of a baseline scenario methodology transcends the borders of this short article and will not be discussed further here.

\section{IMPLICATIONS AND CONCLUSION}

The results presented have shown in several cases that a number of scenarios can be rapidly produced by a small group of participants, even when they are working in their spare time.

Here, we may distinguish between implications in two areas. One is the scenario method itself and its ability to generate scenarios on the macro and sectorial levels. The other is the level of the firm, where scenarios must be constructed.

First, the process resulted in the construction of 20 scenarios in five different areas by 22 people (see again figure 4). All the scenarios were long-run macro scenarios, which created 
frameworks that could be used as inputs in a normal strategy process, thereby facilitating firms' and organisations' decision making. The scenarios were detailed and integrated a great deal of knowledge from economics and other areas (see again the condensed example in figure 5). This opens up the possibility that this scenario construction method may enhance or (in some cases) substitute other methods usually employed in strategic analysis on the macro or meso levels, such as the PESTELE method or methods for industry analysis (Aaker, 2006). More research into these matters may prove fruitful.

Second, the fact that the scenarios were constructed by rather small groups implies that we may have a useful method that can be used to develop scenarios in either small and mediumsized enterprises or larger companies without involving an excess of people. However, experience shows that it may be advantageous to use participants with a diverse background from multiple academic disciplines and with multiple work experiences. Participants should ideally not be 'representative' or 'typical' in any way. This condition may, however, be relaxed somewhat if scenarios are meant to be constructed by a small management team similar in terms of organisational level, but different in terms of education and work experience. Another important point is that the writing process is integral to the whole experience and the results as participants' views often become clearer when things are put on paper. This results in the creation of a double feedback loop between paper and the mind.

Scenario construction may be compared in this manner to the use of focus groups (Barbour, 2007). In both cases, we see that issues are discussed in small groups and that some minor guidance in the process may be necessary. The difference is that while participants in focus groups most often are customers, in scenario construction groups, they are by contrast recruited from management and staff. A further difference is that participants in a scenario 
planning group should ideally be more active, more creative and inclined to gather and process data to support the process. A final difference is that the scenario construction process takes more than a day.

In sum, the key findings and recommendations for scenario construction in firms and other organisations are:

- Use a 'game manager' and settings comparable to those found in the focus group methodology.

- Use a team of around five people with diverse backgrounds.

- Use the 7-point consistency test.

- Use the 14-point method.

- Use secondary sources of data, information and knowledge.

- Be prepared to spend around 30 hours on free discussion and writing. (This time period may either span three full days or be stretched over several weeks or even months if need be.)

- Be output oriented. Scenarios should be produced as narratives in writing.

There are limitations to this study. The introduction of this article mentioned two: the use of qualitative methodology and the embeddedness in a strategic forecasting framework, both of which decrease the generalisability of the study. However, as mentioned in the introduction, the first may be unavoidable and the second may also be seen as a strength. Consequentially, the use of this method is limited to strategic forecasting but it may conversely be seen as an important addition to the toolbox in that area. 
This method has across several cases been shown to be able to generate scenarios fast. Hence, despite the limitations of this method, its use may not only enable firms to produce scenarios much faster and at reduced costs; small and medium-sized firms may also make greater use of scenarios. Thus scenarios may in the future be produced more easily and by a broader circle of firms, as suggested by earlier authors (Foster, 1993; Mercer, 1995a, 1995b). The difference is that the method presented in this article and the scenarios produced by it are more detailed than those earlier attempts. Hence, improvements in the quality and the applicability of the scenarios are to be expected. Future research into the method and its application can be suggested.

\section{REFERENCES}

Aaker, D.(2006) Strategic Market Management, John Wiley \& Sons, Berkeley.

Aligica, P. D. (2007) 'Uncertainty, Human Action and Scenarios: An Austrian Theory Based Decision Support Tool for Business Strategy and Public Policy', Review of Austrian Economics, Vol. 20, No. 4, pp. 293-312.

Ansoff, I. and McDonnell, E. J. (1990) Implanting Strategic Management, Prentice-Hall, New York.

Armstrong, J. S. (2001) Principles of Forecasting: A Handbook for Researchers and Practioners, Kluwer/Springer, Norwell.

Barbour, R. (2007) Doing Focus Groups, Sage Publications, Los Angeles. 
Bootz, J-P. (2010) 'Strategic Foresight and Organizational Learning: A Survey and Critical Analysis', Technological Forecasting and Social Change, Vol. 77, No. 9, pp. 1588-1594.

Bradfield R., Wright G., Burt G., Cairns G. and Heijden K. (2005) 'The Origins and Evolution of Scenario Techniques in Long Range Business Planning', Futures, Vol. 37, No. 8, pp. 795-812.

Brauers, W.K. (2004) Optimization Methods for a Stakeholder Society: A Revolution in Economic Thinking by Multi-objective Optimization, Kluwer, Boston.

Bunn; D. W. and Salo, A.A. (1993) 'Forecasting with scenarios', European Journal of Operational Research, Vol. 68, No. 3, pp. 291-303.

Capon, N. and Hulbert, J. M.(1985) 'The Integration of Forecasting and Strategic Planning', International Journal of Forecasting, Vol. 1, No. 2, pp. 123-133.

Capon, N. and Palij, P.(1994) ‘Strategic Marketing Forecasting, Market Segment Selection and Firm Performance', International Journal of Forecasting, Vol. 10, No. 2, pp. 339-352.

Chang, H. (2008) Autoethnography as Method, Left Coast Press: Walnut Creek, CA.

Chermack, T.J.; Lynham, S.A. and Ruona, W.E. A. (2001) ‘ A Review of Scenario Planning Literature', Futures Research Quarterly, Vol. 17, No. 2, pp. 7-32. 
Cummings, S and Daellenbach, U. (2009) 'A Guide to the Future of Strategy? The History of Long Range Planning' Long Range Planning, Vol. 42, No. 2, pp. 234-263.

Duijn, P.A. and Hartigh, E. (2009) ' Keeping the Balance: Exploring the Link of Futures Research with Innovation and Strategy Processes', Technology Analysis \& Strategic Management, Vol. 21, No. 3, pp. 333-351.

Duus, H. J. (1997) 'Economic Foundations for an Entrepreneurial Marketing Concept', Scandinavian Journal of Management, Vol. 13, No. 3, pp. 287-305.

Duus, H. J. (1999) 'Strategic Business Market Forecasting', Journal of Strategic Change, Vol. 8, No. 3, pp. 173-182.

Duus, H. J. (2013) 'Strategic Forecasting - Theoretical Development and Strategic Practice', International Journal of Business Innovation and Research, Vol. 7, No. 3, pp. 362-378.

Foster, M. J. (1993) ‘Scenario Planning for Small Businesses’, Long Range Planning, Vol. 26, No. 1, pp. 123-129.

Georgantzas, N. C. and Acar, W.(1995) Scenario-Driven Planning - Learning to Manage Strategic Uncertainty, Quorum Books, Westport.

Godet, M and Roubelat, F. (1996) 'Creating the Future: The Use and Misuse of Scenarios', Long Range Planning, Vol. 29, No. 2, pp. 164-171. 
Graf, H. G. (2002a) Economic Forecasting for Management - Possibilities and Limitations, Quorum Books, Westport.

Graf, H. G. (2002b) Global Scenarios: Megatrends in Worldwide Dynamics, Rüegger, Zürich.

Heijden, K. V. D. (2005) Scenarios: The Art of Strategic Conversation, (2 edition) John Wiley \& Sons, Chichester.

Itoh, T.(1996) A New Approach to Future Enterprises - Abduction for Creativity, Omsha, Tokyo.

Kahn, H. (1965) Thinking about the Unthinkable, Horizon Press, New York.

Lindgren, M. and Bandhold H. (2009) Scenario Planning - The Link BETWEEN Future and Strategy, New York, Palgrave.

Martinet, A-C (2010) 'Strategic Planning, Strategic Management, Strategic Foresight: The Seminal Work of H. Igor Ansoff', Technological Forecasting and Social Change, Vol. 77, No. 9, pp. 1485-1487.

Martino, J. P. (1992) Technological Forecasting for Decision Making, McGraw-Hill, New York.

Mercer, D. (1995a) 'Scenarios made easy’, Long Range Planning, Vol. 28, No. 4, pp. 81-86. 
Mercer, D. (1995b) 'Simpler Scenarios', Management Decision, Vol. 33, No.4, pp. 32-40.

Porter, M. E. (1985) Competitive Advantage, The Free Press, New York.

Pring, M. J. (2002) Technical Analysis Explained, McGrawHill, New York.

Rasmussen, B., Andersen, P. and Borch, K. (2010) 'Managing Transdisciplinarity in Strategic Foresight', Creativity and Innovation Management, Vol. 19, No. 1, pp. 37-46.

Ringland, G.(2002) Scenarios in Business, (1 edition) Chichester, Wiley.

Rohrbeck, R. (2012) 'Exploring Value Creation from Corporate-Foresight Activities'

Futures, Vol. 44, No. 5, pp. 440-452.

Rohrbeck, R. and Gemünden, H. (2011) ‘ Corporate Foresight: Its Three Roles in Enhancing The Innovation Capacity of a Firm', Technological Forecasting and Social Change, Vol. 78, No. 2, pp. 231-243.

Schnaars, S. P. (1987) 'How to Develop and Use Scenarios', Long Range Planning, Vol. 20, No. 1, pp. 105-114.

Schoemaker, P. J.H. and Heijden, C.A.J.M. van der (1992) 'Integrating Scenarios into Strategic Planning at Royal Dutch/Shell', Strategy and Leadership, Vol. 20, No. 3, pp. 41-46. 
Schoemaker, P. J. H. (1993) 'Multiple Scenario Development: Its Conceptual and Behavioral Foundation', Strategic Management Journal, Vol. 14, No. 3, pp. 193-213.

Schoemaker, P. J. H. (1995) 'Scenario Planning: A Tool for Strategic Thinking', Sloan Management Review, Vol. 36, No. 2, pp. 25-40.

Schwartz, J. (2007) 'Assessing the Future of Future Studies in Management', Futures, Vol. 40, No. 3, pp. 237-246.

Sharpe, B. and Heijden K. (2007) Scenarios for Success-Turning Insights into Action, Wiley, Chichester.

Shim, J. K. (2000) Strategic Business Forecasting - The Complete Guide to Forecasting Real World Company Performance, St. Lucie Press, New York.

Tvede, L. (2010) Supertrends: Winning Investment Strategies for The Coming Decades, Wiley, Chichester.

Varum, C.A. and Melo, C. (2010) 'Directions in Scenario Planning Literature - A Review of the Past Decades', Futures, Vol. 42, No. 4, pp. 355-369.

Vecchiato, R. and Roveda, C. (2010) 'Foresight in Corporate Organizations', Technology Analysis \& Strategic Management, Vol. 22, No. 1, pp. 99-112. 
Wack, P. (1985) ' Scenarios: Uncharted Waters Ahead', Harvard Business Review, Vol. 63, No. 5, pp. 73-89.

Wack, P. (1985) ' Scenarios: Shooting the Rapids', Harvard Business Review, Vol. 63, No. 6, pp. 139-150.

Yin, R. K. (2009) Case Study Research: Design and Methods, Sage Publications, Los Angeles.

Yu, C. H. (1994), 'Is There a Logic of Exploratory Data Analysis?', Annual Meeting of American Educational Research Association, New Orleans, LA, April, http://www.creativewisdom.com/pub/Peirce/Logic_of_EDA.html (accessed 21 January, 2014). 
FIGURE 1:

STRATEGIC FORECASTING

COMPARED TO OTHER FORMS OF ANALYSIS (DuUs, 2013)

\begin{tabular}{|c|c|c|}
\hline Type of a & $\begin{array}{l}\text { Traditional Market Analysis } \\
\text { (including traditional } \\
\text { forecasting) }\end{array}$ & Strategic Forecasting \\
\hline Time horizon & Short-term & Long-term \\
\hline Organisational level & Operative/tactical & Strategic \\
\hline Object of analysis & $\begin{array}{l}\text { The proximate environment of } \\
\text { the firm }\end{array}$ & General business conditions \\
\hline Application & $\begin{array}{l}\text { Traditional products and } \\
\text { activities }\end{array}$ & $\begin{array}{l}\text { Innovation understood as } \\
\text { economic value-increasing } \\
\text { novelties. }\end{array}$ \\
\hline Practical examples & $\begin{array}{l}\text { Questionnaires for consumers, } \\
\text { focus groups, media analyses, } \\
\text { qualitative interviews, neo- } \\
\text { classical econometrics, etc. }\end{array}$ & $\begin{array}{l}\text { Strategic business cycle } \\
\text { forecasting, strategic warning, } \\
\text { scenario analysis, futures } \\
\text { research, technological } \\
\text { forecasting, financial market } \\
\text { analysis (i.e. technical analysis), } \\
\text { demographic forecasting, etc. }\end{array}$ \\
\hline
\end{tabular}


FIGURE 2: THE COURSE IN STRATEGIC FORECASTING

\begin{tabular}{|c|c|}
\hline Host institution & $\begin{array}{l}\text { Copenhagen Business School } \\
\text { (Danish university with approx. 20,000 students) } \\
\text { Located in the municipality of Frederiksberg in the centre of Copenhagen. }\end{array}$ \\
\hline Venue and time & $\begin{array}{l}\text { Frederiksberg (Dalgas Have) auditorium and adjacent rooms } \\
2011 \text { Autumn semester, } 7 \text { consecutive Thursdays starting } 1 \text { September, } \\
5 \text { p.m. to } 8 \text { p.m. }\end{array}$ \\
\hline Education & $\begin{array}{l}\text { HD (International Business specialisation) } \\
\text { Bachelor level part time elective course for business people. }\end{array}$ \\
\hline Course composition & $\begin{array}{c}\text { Seven sessions of three hours each in total. Five consisting of various } \\
\text { lectures (one, two or three per session, depending on subject and lecturer) } \\
\text { and two open coaching sessions. In addition, some unscheduled group work } \\
\text { by participants, resulting in the written scenarios. Individual oral exam based } \\
\text { on the group work. }\end{array}$ \\
\hline Participants & $\begin{array}{l}\frac{22 \text { active out of } 24 \text { registered }}{\text { All participants had active business careers involving finance, marketing, }} \\
\text { production, management etc. The educational background was diverse and } \\
\text { ranged from Master's degrees in engineering and science to previous } \\
\text { undergraduate courses in economics and business. }\end{array}$ \\
\hline Academic staff (faculty) & $\begin{array}{l}\text { Two in total } \\
1 \text { associate professor, PhD in innovation, Master's degree in } \\
\text { economics } \\
1 \text { adjunct professor, two Master's degrees in economics and statistics. }\end{array}$ \\
\hline $\begin{array}{l}\text { External experts (guest } \\
\text { lecturers) }\end{array}$ & $\begin{array}{l}\text { Five in total } \\
1 \text { consultant, Master's degree in European ethnology and history. } \\
1 \text { manager (finance), Master's degree in economics and business adm. } \\
1 \text { manager (marketing), Master's degree in economics and business } \\
\text { adm. } \\
1 \text { futurist/consultant, Bachelor's degree in astrophysics. } \\
1 \text { consultant/investor, Master's degree in financial technical analysis. }\end{array}$ \\
\hline
\end{tabular}




\section{FIGURE 3:}

\section{INPUT AREAS TO THE SCENARIO CONSTRUCTION PROCESS}

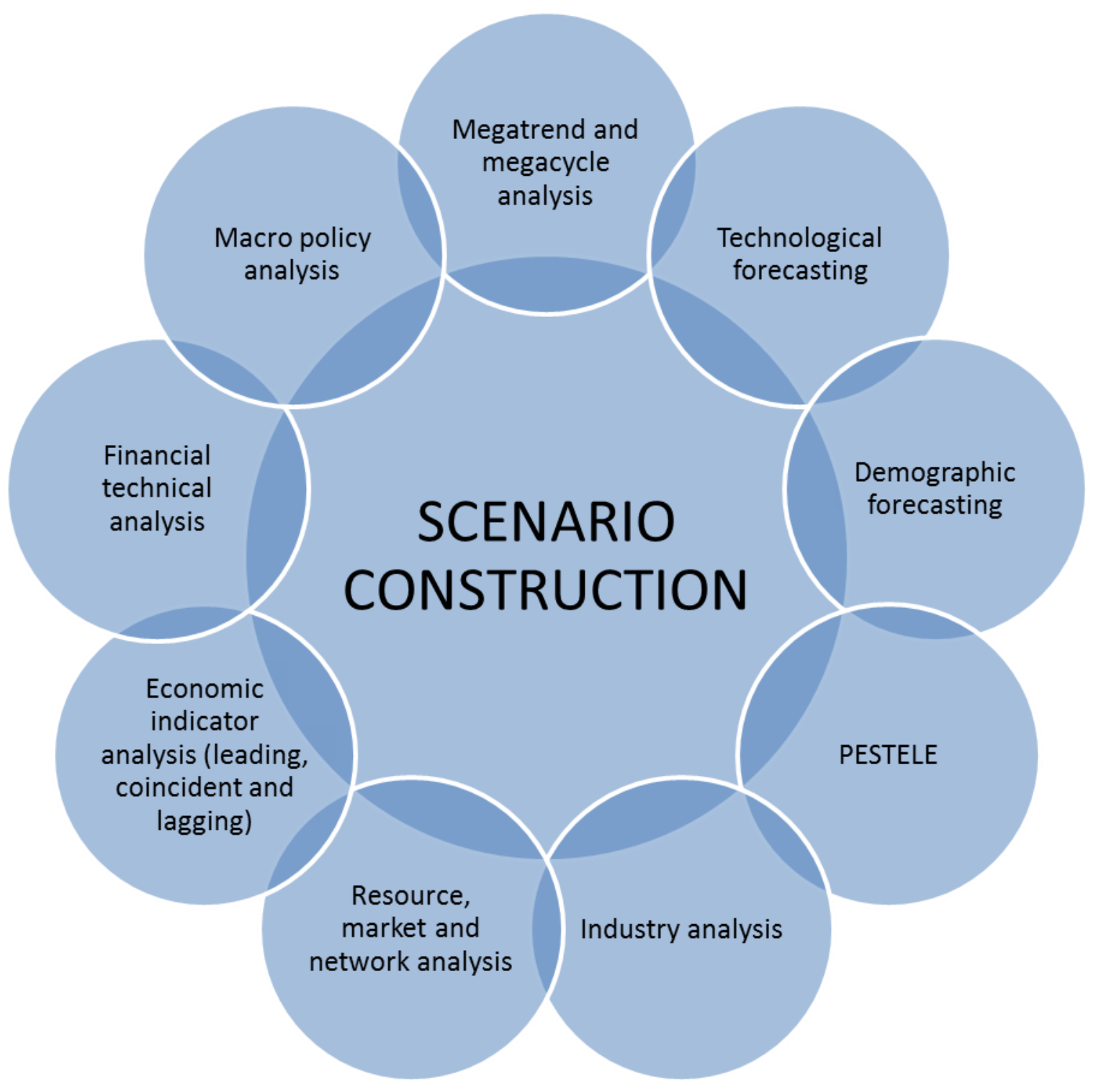


FIGURE 4

SCENARIO GROUP ACTIVITY

\begin{tabular}{|c|c|c|c|c|}
\hline Group & Persons & Pages & Topic & Scenarios \\
\hline 1 & 5 & 41 & $\begin{array}{l}\text { Scenarios for } \\
\text { energy prices } \\
\text { towards } 2030\end{array}$ & $\begin{array}{l}\text { Green world agenda } \\
\text { Growth and welfare } \\
\text { Energy independence } \\
\text { End is near: peak oil }\end{array}$ \\
\hline 2 & 6 & 53 & $\begin{array}{l}\text { The future of } \\
\text { international } \\
\text { transportation }\end{array}$ & $\begin{array}{l}\text { Doomsday } \\
\text { Status quo } \\
\text { New balance } \\
\text { The best of all worlds }\end{array}$ \\
\hline 3 & 5 & 46 & $\begin{array}{l}\text { Developments in } \\
\text { China: The next } \\
\text { ten years }\end{array}$ & $\begin{array}{l}\text { "Can do - will do" } \\
\text { Fall of the wall } \\
\text { Bull in a China shop } \\
\text { Play for ourselves }\end{array}$ \\
\hline 4 & 4 & 30 & $\begin{array}{l}\text { The } \\
\text { development } \\
\text { of agriculture }\end{array}$ & $\begin{array}{l}\text { Victory } \\
\text { Ecology not just in foods } \\
\text { The fall of the associations } \\
\text { Technology rules }\end{array}$ \\
\hline 5 & 2 & 22 & $\begin{array}{l}\text { The future } \\
\text { production of } \\
\text { electrical power }\end{array}$ & $\begin{array}{l}\text { Oil country paradise } \\
\text { Environmental enforcement } \\
\text { Spendthrift paradise } \\
\text { The right choice }\end{array}$ \\
\hline
\end{tabular}


FIGURE 5:

SHORT EXAMPLE OF SCENARIOS FROM GROUP 3

Growth in China

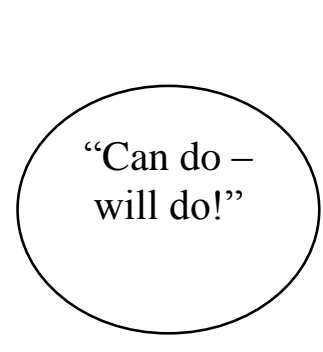

Protectionism

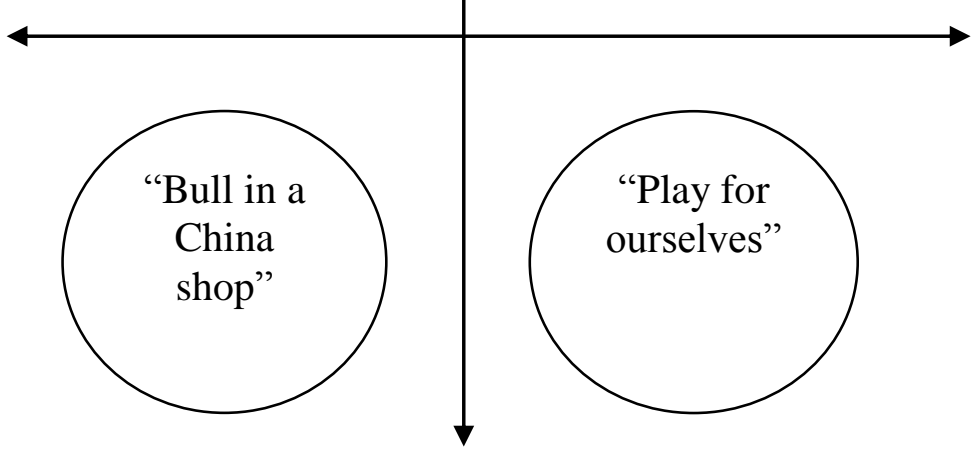

Free Trade

Stagnation in China

CAN DO - WILL DO: High growth in China, increased protectionism, Chinese leaders promoting a "Chinese way", increased Chinese nationalism, increased military build-up, increased focus on environmental protection, increased centralisation.

FALL OF THE WALL: High growth, more market economy, more inflation, increased urbanisation, slow rise in interest rates, China integrates more into world society, general reform course in environmental protection and politics.

BULL IN A CHINA SHOP: Stagnation and low growth in China, lower currency, high inflation in China, increased problems with health care especially for the elderly, increased corruption, increased problems with pollution, human rights issues, discrimination against Western companies.

PLAY FOR OURSELVES: Currency revaluation, more elderly leaving the labour market, political stability, less regulation, real estate and stocks crash after asset inflation, slow-down of Chinese consumption, Western companies and investments moving to other countries in the region. 